\title{
BIORREMEDIAÇÃO, UMA ALTERNATIVA NA UTILIZAÇÃO EM ÁREAS DEGRADADAS PELA INDÚSTRIA PETROLÍFERA
}

\author{
M. C. MORAIS FILHO e A. C. F. CORIOLANO* \\ Laureate International University, Universidade Potiguar - UnP \\ catarina.coriolano@unp.br ${ }^{*}$
}

Artigo submetido em março/2016 e aceito em setembro/2016

DOI: $10.15628 /$ holos.2016.4278

\section{RESUMO}

As áreas contaminadas pela indústria petrolífera têm sido um problema cada vez mais constante, devido à demanda cada vez maior em busca do petróleo e seus derivados, pela indústria petroquímica e pela utilização do petróleo como fonte energética atual. Desta forma, se torna relevante o conhecimento de técnicas que sejam eficientes para a descontaminação de áreas afetadas pela indústria petrolífera. $O$ presente trabalho tem como base um estudo bibliográfico detalhado sobre o tema, tendo como objetivo expor e analisar os processos relacionados à biorremediação in situ ou ex situ, a qual é responsável por mitigar os impactos ambientais oriundos da indústria petrolífera. Conclui-se que através da análise dos processos que compõem a biorremediação, não se pode asseverar que um método torna-se mais relevante do que o outro, tendo em vista que para que ocorram níveis ótimos de biorremediação, é impreterível conhecer as características de concentração do contaminante, assim

PALAVRAS-CHAVE: Petróleo, Contaminantes ambientais, Biorremediação.

\section{BIOREMEDIATION, AN ALTERNATIVE TO USE IN THE OIL INDUSTRY DEGRADED AREAS}

\begin{abstract}
The areas contaminated by the oil industry have been an increasing problem due to the growing demand for oil and its derivatives by the petrochemical industry, and the use of oil as a current energy source. Thus, it's important to know techniques that are efficient for decontaminating areas affected by the oil industry. This study is based on a detailed bibliographic study on the topic, aiming to expose and analyze the processes related to bioremediation in situ or ex situ, which is responsible
\end{abstract}

for mitigating the environmental impacts from the oil industry. It is concluded that, by analyzing the processes that make up the bioremediation, it is not possible to assert that a method becomes more significant than the other in order to occur optimum levels of bioremediation, it is imperative to know the characteristics of contaminant concentration, as well as the population density of microorganisms used to degrade oil and their potential for biodegradation.

KEYWORDS: Oil, Environmental contaminants, Bioremediation. 


\section{INTRODUÇÃO}

O petróleo, derivado de distintos tipos de matéria orgânica, é constituído basicamente de carbono e hidrogênio - hidrocarbonetos, gerados através de processos bioquímicos, químicos e físicos que atuam sobre essa matéria orgânica, tanto na sua deposição como durante seu soterramento.

O petróleo já vem sendo utilizado desde os tempos pré-históricos pelas mais diferentes civilizações, como: fenícios, egípcios, gregos, romanos, incas e maias. Ele foi empregado na cimentação de construções, pavimentação de estradas, impermeabilizante de barcos, preservação de múmias, na iluminação, como arma de guerra e para diversos outros fins. Em 1859, o Coronel Edwin L. Drake perfurou o primeiro poço de petróleo próximo à cidade de Tittusville, Pensilvânia, EUA. Com esse poço, que tinha apenas 21 metros de profundidade, Drake obteve um fluxo constante de óleo e promoveu o nascimento da moderna indústria de petróleo, o que marcou o processo de busca e a crescente afirmação do produto na sociedade moderna (THOMAS, 2004).

O petróleo ainda é a mais importante fonte de energia da atualidade, pois é por meio dele que se possibilita a realização de inúmeras atividades. Ele é utilizado principalmente na formação de combustíveis, como gasolina, gás natural, gás de petróleo liquefeito, óleo diesel, óleo combustível e querosene de aviação. Além disso, o petróleo é uma importante matéria-prima utilizada na fabricação de produtos: plásticos, tintas, borrachas sintéticas, farmacêuticos, cosméticos e alguns outros provenientes do advento da indústria petroquímica.

No entanto, apesar de tantos benefícios o petróleo traz em suas composições contaminantes como enxofre e metais pesados, o que acarreta grandes riscos para o meio ambiente desde o processo de extração, transporte, refino, até o consumo, com a produção de gases que poluem a atmosfera. Os piores danos acontecem durante o transporte de combustível, com vazamentos em grande escala de oleodutos e navios petroleiros (THOMAS, 2004).

Silva et al. (2008), mostram que os impactos ambientais estão diretamente interligados ao setor petrolífero, causando a degradação ambiental por vários fatores, os mais comumente são: derramamento de petróleo, que causa a destruição do ecossistema marinho ou terrestre, desmatamento que são oriundos por suas instalações, poluição do ar e descarte de resíduos.

Diante disso, diversas técnicas físicas, químicas e biológicas, vêm sendo desenvolvidas para a atenuação e remoção de ambientes contaminados por petróleo. Dentre as técnicas desenvolvidas, a técnica da biorremediação se utiliza de microrganismos (bactérias e fungos) para realizar a remoção de contaminantes tóxicos do meio ambiente, o que a torna, uma alternativa viável economicamente e promissora para o tratamento de solos contaminados por petróleo e seus derivados (ANDRADE; AUGUSTO; JARDIM, 2010).

Portanto, a perspectiva do presente trabalho visa expor e analisar, por meio de estudos bibliográficos, o uso dos processos de biorremediação in situ e ex situ para redução de contaminantes presentes no petróleo produzido, bem como a melhora no âmbito social e ambiental, visto que os contaminantes do petróleo em geral causam degradação da fauna e flora, afetando a vida no planeta. 


\section{REVISÃO DA LITERATURA}

\subsection{O PETRÓLEO E SEUS CONTAMINANTES}

O petróleo é uma mistura complexa que é formada a partir de vários compostos, no entanto, os hidrocarbonetos representam sua grande maioria. Porém, de acordo com a origem no qual o petróleo foi formado, existirão mudanças de composição e propriedades, químicas e físicas, respectivamente, que variam de um campo petrolífero para outro. Dessa forma, o tratamento de áreas contaminadas por essas substâncias, por sua vez, acaba se tornando complexo, devido a sua composição diversificada (ANDRADE; AUGUSTO; JARDIM, 2010). Thomas (2004) demonstra esta composição do petróleo de forma detalhada, conforme o Quadro 1.

Quadro 1: Composição do petróleo cru típico (\% em peso).

\begin{tabular}{|c|c|}
\hline Hidrogênio & $11-14 \%$ \\
\hline Carbono & $83-87 \%$ \\
\hline Enxofre & $0,006-8 \%$ \\
\hline Nitrogênio & $0,11-1,7 \%$ \\
\hline Oxigênio & $0,1-2 \%$ \\
\hline Metais & Até $0,3 \%$ \\
\hline
\end{tabular}

Fonte: Adaptado de Thomas (2004, p.5).

Para o autor, a elevada porcentagem de hidrogênio e carbono na composição do petróleo cru típico, demostra que os seus principais constituintes são os hidrocarbonetos. Os outros compostos que o constituem aparecem na forma de compostos orgânicos contendo outros elementos, porém os mais comumente encontrados são o nitrogênio, o enxofre e o oxigênio, além dos metais que podem ocorrer com sais de ácidos orgânicos.

Do ponto de vista de Cardoso (2005), o petróleo também é uma substância natural e se apresenta de determinadas formas, como: sólido, líquido ou gás. Constituído por hidrocarbonetos e impurezas presentes, esses compostos presentes nos hidrocarbonetos, por sua vez, produzem corrosividade, acidez, odor, poluentes e cor. Comumente são: água, asfaltenos, enxofre, nitrogênio, dióxido de carbono, oxigênio e compostos metálicos.

Em solos contaminados por petróleo e seus derivados, o benzeno, tolueno, etilbenzeno e xilenos conhecidos como BTEX são definidos como hidrocarbonetos monoaromáticos, se destacam como grande problema no Brasil e no mundo por serem tóxicos tanto para o meio ambiente como ao ser humano (ANDRADE; AUGUSTO; JARDIM, 2010).

Entre diversas técnicas para remediar os impactos provenientes da indústria petrolífera, se faz o uso da técnica de biorremediação, que consiste no processo de descontaminação de áreas impactadas por poluentes. Essa remediação se dá por meio de microrganismo ou plantas, sendo possível ser realizado in situ ou ex situ, ou as duas formas em conjunto. O que irá determinar o processo são as características físicas e químicas do ambiente, assim como a composição do contaminante. 


\subsection{MICRORGANISMOS}

Microrganismo é o nome dado aos microrganismos formados, em sua maioria, por uma única célula e que não podem ser vistos a olho nu, sendo visíveis apenas com o auxílio de um microscópio. Estes podem ser encontrados no ar, no solo, na água e inclusive no homem, estando distribuído por toda parte do planeta.

Esses, por sua vez, foram os primeiros seres vivos a habitar a Terra. Estima-se que seu surgimento é datado de mais de 3,5 milhões de anos. Hoje, os microrganismos originam-se em praticamente todo o planeta, sendo capazes de sobreviver em ambientes extremos, esses aos quais animais e plantas não sobreviveriam. Esses ambientes são diversificados, desde fontes geotermais, desertos, regiões polares, lagos alcalinos, até subsolo e interior de rochas e em depósitos de petróleo (MANFIO, 2003).

Nesse contexto, nota-se a significância da origem dos microrganismos e o modo adaptativo no qual eles sobrevivem aos demasiados meios ambientais ao qual são inseridos, do ambiente mais hostil, com temperaturas e pressões elevadas, a ambientes tranquilos e límpidos, como fundos de rios e lagos. Portanto, fica clara a facilidade que os microrganismos têm de se originar em determinados meios, assim como sobreviver a estes.

A área que estuda esses pequenos organismos é chamada de microbiologia. Segundo Bossolan (2002), o estudo da microbiologia atua principalmente em dois campos: a microbiologia básica e a microbiologia aplicada. Para o autor:

A microbiologia básica estuda as propriedades e atividades de formação e multiplicação dos microrganismos, como: as características morfológicas; características fisiológicas; atividades bioquímicas; características genéticas; características ecológicas; potencial e de classificação entre cada grupo.

Já a microbiologia aplicada analisa como os microrganismos podem ser utilizados em variadas áreas. Os principais campos de aplicação dessa microbiologia são: médica; alimentícia; petrolífera e ambiental.

Ainda de acordo com o autor, a microbiologia na medicina trata dos microrganismos que causam doenças ao ser humano, relacionada sempre a prevenção e controle das mesmas.

Em consonância com esses acontecimentos, a microbiologia dos alimentos estuda como as doenças podem ser transmitidas por meio desses, assim como, a utilização dos microrganismos na produção de alimentos e bebidas (BOSSOLAN, 2002).

$\mathrm{Na}$ indústria do petróleo tem-se utilizado bactérias e seus produtos, como os exopolissacarídeos $^{1}$, que tem a capacidade de aumentar a extração do petróleo de rochas reservatório. Há também, certos microrganismos que são capazes de fermentar material orgânico (plantas e animais), e com isso, obter produção de gás metano, que pode ser coletado e usado como combustível.

Para Myers (1996), os microrganismos tem um papel fundamental para a manutenção dos ecossistemas da biosfera, sendo estes os principais componentes de cadeias alimentares e de

\footnotetext{
${ }^{1}$ Exopolissacarídeos são definidos como polissacarídeos extracelulares produzidos por alguns fungos e bactérias, os quais são encontrados ligados à superfície das células ou são excretados para o meio.
} 
ciclos biogeoquímicos ${ }^{2}$. Uma dessas funções no qual eles são empregados é a biorremediação, que promove a degradação dos contaminantes, por intermédio da respiração microbiana (bactérias, fungos e leveduras), contribuindo assim para a manutenção do equilíbrio ambiental.

\subsubsection{Participação dos microrganismos na formação do petróleo}

A participação dos microrganismos é de fundamental importância para formação dos hidrocarbonetos. O petróleo é gerado a partir de restos de matéria orgânica de origem animal ou vegetal que se depositam em fundo de lagos e rios, formando uma camada de material orgânico e com o passar do tempo serão sobrepostas por outras camadas de sedimentos, e pela ação de bactérias e microrganismos, aliados a alta pressão e temperaturas elevadas, este composto orgânico transforma-se em hidrocarboneto.

De acordo com Thomas (2004), o petróleo é formado por matéria orgânica marinha, que é oriunda de microrganismo e algas. Contudo, para que haja esta formação, os microrganismos não podem sofrer processos oxidativos. Por conseguinte, para que este cenário não ocorra, presumese um ambiente de deposição composto por sedimentos de baixa permeabilidade e com uma inibição de circulação de água em seu interior, favorecendo com isto, sua compactação.

Todavia, Cardoso (2005) alega que não só os microrganismos tem suma importância na geração do petróleo, mas também as rochas sedimentares. Com isto, o nome dado à rocha que comporta todo o processo de formação do petróleo é a rocha geradora.

Portanto, por meio da interação destes fatores, matéria orgânica, sedimentação e condições termoquímicas favoráveis, torna-se possível à formação do petróleo. A Figura 1 representa os estágios de transformação da matéria orgânica que ocorre de acordo com os níveis de temperatura e profundidade, sendo a catagênese a principal janela para sua formação.

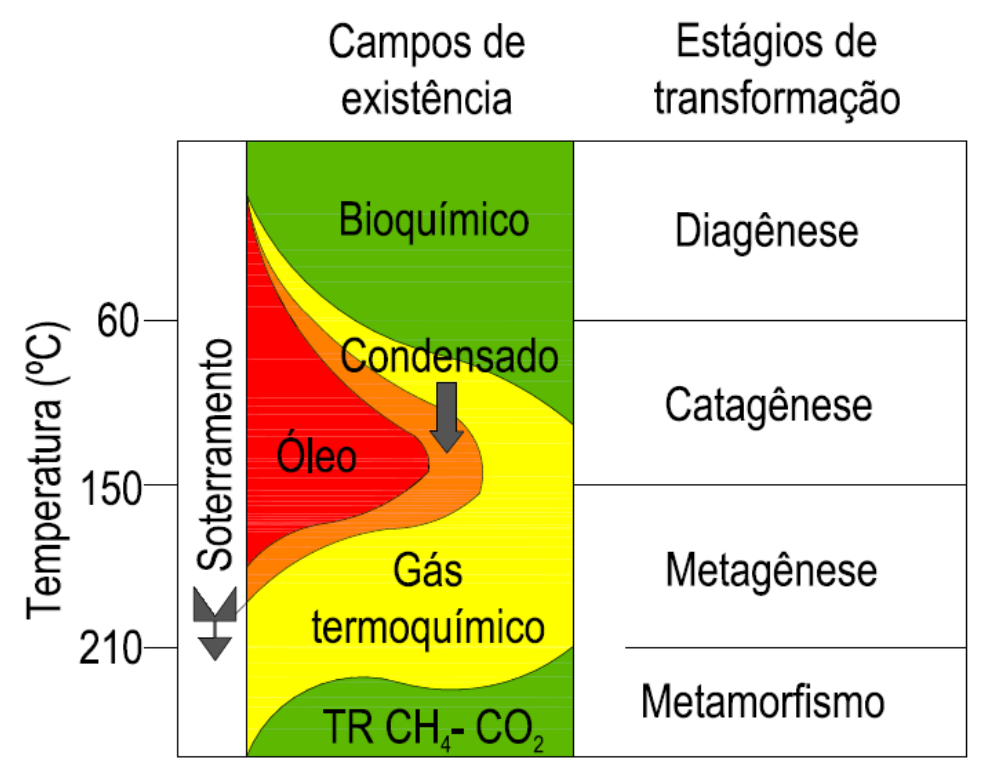

Figura 1: Transformação termoquímica da matéria orgânica e a geração do petróleo. Fonte: Adaptado de Thomas (2004, p.16).

${ }^{2} \mathrm{O}$ ciclo biogeoquímico é o percurso realizado no meio ambiente por um elemento químico essencial à vida. 


\subsection{IMPACTOS AMBIENTAIS ORIUNDOS DA INDÚSTRIA PETROLÍFERA}

O petróleo, por ser uma substância tóxica, põe em risco todo o ecossistema ao seu redor. Dois dos principais causadores dos impactos ambientais são a exploração e explotação de petróleo. Muitos desastres ambientais são causados devido a falhas nesses processos, causando acidentes e vazamentos que podem contaminar todo ecossistema presente.

De acordo com Santos (2012), o processo de exploração e produção estão relacionados diretamente na causa de impactos ambientais. Este efeito nocivo ao meio ambiente pode se apresentar de várias maneiras: derramamento de óleo ocasionado por vazamento, ocasionando desastres ecológicos como, poluição ambiental; degradação ambiental; destruição da fauna e da flora. O desmatamento na fase inicial de refinarias e plataformas onshore, também causam impactos ambientais, assim como, impacto na colocação de dutos sobre os ecossistemas marinhos e terrestres. O lançamento de resíduos no meio ambiente pela indústria petrolífera também é um potencial poluidor de rios e oceanos; o solo e ar, podendo alterar os ecossistemas vizinhos, e até mesmo, comprometer a extinção de espécies.

\subsection{BIORREMEDIAÇÃO}

A biorremediação é uma técnica de descontaminação de ambientes contaminados que se utiliza de organismos vivos, plantas ou microrganismo (bactérias e fungos), com a finalidade de atenuação ou recuperação de determinados contaminantes presentes no meio ambiente. Todavia, para que haja eficiência nesse processo, alguns fatores tornam-se condicionantes como, temperatura, presença de oxigênio, nutrientes, e pH (BERGER, 2005; MUTECA, 2012).

A comunidade cientifica atual tem pesquisado e recomendado intensamente este processo biotecnológico, como uma alternativa viável para a descontaminação de ambientes; tais como águas superficiais, subterrâneas e solos, além de efluentes e resíduos industriais em aterro ou áreas de contenção. Não obstante, existem outras técnicas que utilizam processos físicos e/ou químicos para descontaminar ambientes poluídos. Contudo, a biorremediação é uma alternativa eficaz para o combate de ambientes contaminados com moléculas de difícil degradação denominadas "recalcitrantes", bem como também os metais tóxicos (GAYLARDE; BELLINASO; MANFIO, 2005).

De acordo com Rosato (1997 apud COSTA FILHO, 2011), existem diversos métodos para a descontaminação de um ambiente, no entanto, poucas são tão eficientes quanto à biorremediação, que surge como uma técnica de baixo custo, menor agressividade ao meio e uma maior adaptação para manutenção do equilíbrio ambiental.

Muteca (2012), afirma que a degradação pode ocorrer por intermédio do metabolismo de respiração aeróbia ou anaeróbia. Assim, para que haja a biodegradação completa ou a mineralização, o composto original precisa ser oxidado formando dióxido de carbono e água, ocorrendo assim à produção de energia que é utilizada na síntese do material celular (biomassa). Com isso, a degradação é catalisada por uma enzima especifica existente no conjunto metabólico da célula degradante. A Figura 2 representa de forma simplificada a ação do microrganismo no processo de biorremediação. 


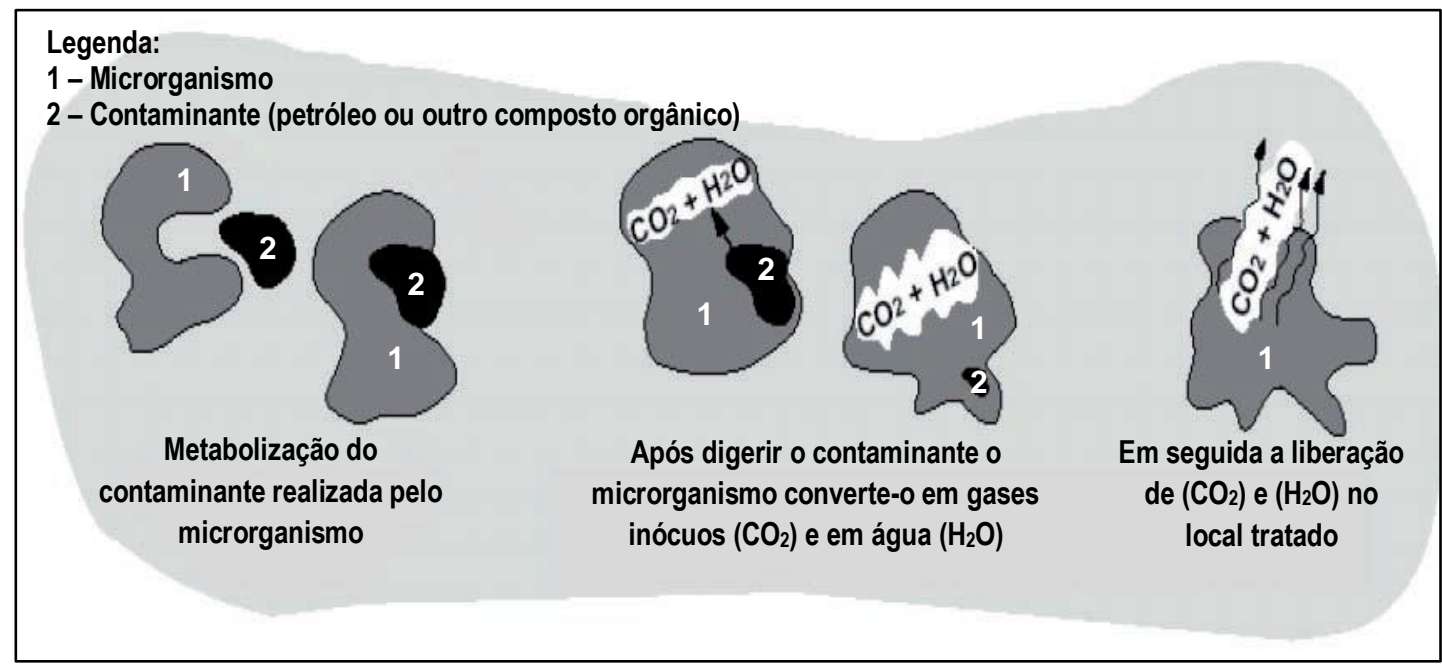

Figura 2: Etapas da ação do microrganismo no processo de biorremediação. Fonte: Adaptado de Andrade, Augusto e Jardim (2010, p.24).

Segundo Prince (1993 apud COSTA FILHO, 2011) existiram casos aos quais a técnica de biorremediação foi aplicada e após um ano se obteve a eficácia de $90 \%$ de redução da contaminação existente, enquanto nas regiões em que não se obteve o seu uso, tiveram apenas 15\% dessa redução.

Logo, considera-se que a biorremediação tornou-se o aprimoramento da biodegradação, e os seus três principais agentes desta aceleração são:

Bioestímulo (acréscimo de nutrientes);

Bioaumento (introdução de microrganismos);

Biorremediação intrínseca (atenuação natural/monitorada).

Os processos relacionados à biorremediação podem ser classificados de acordo com o tratamento e a fase empregada. De acordo com o local de tratamento, os processos de biorremediação são denominados in situ (quando é realizado no próprio local) ou ex situ (quando há remoção do contaminante para tratamento em outro ambiente). Para cada processo deve se levar em conta qual tipo e quantidade de poluente, os custos para implementá-lo, sobretudo, a concentração final ao término do tratamento, pois é partir desses fatores, que se possibilitará o uso futuro dessa área.

\subsubsection{Vantagens e desvantagens da biorremediação}

A biorremediação oferece algumas vantagens sobre outras técnicas de remediação, como demonstrado no Quadro 2. É ecologicamente correta, pois não altera o equilíbrio dos ecossistemas, visando somente à biodegradação dos compostos poluentes, portanto a redução da concentração e/ou toxicidade. 
Quadro 2: Vantagens e Desvantagens da Biorremediação.

\begin{tabular}{|l||}
\hline \multicolumn{1}{|c|}{ VANTAGENS } \\
A limpeza ocorre in situ, o que elimina o transporte de resíduos perigosos e custos de \\
responsabilidade; \\
Resíduos orgânicos perigosos podem ser destruídos (por exemplo, convertidos em \\
$\mathrm{H}_{2} \mathrm{O}, \mathrm{CO}_{2}$, e sais minerais) em vez de transferidos de uma fase para outra, assim \\
eliminando a responsabilidade em longo prazo; \\
Conta com os processos de biodegradação endógenos que podem ser mais rápidos e \\
mais baratos (no mínimo dez vezes menos caro); \\
Mínimo distúrbio ambiental e do solo; \\
Pode ser usado em conjunto com outras tecnologias de tratamento. \\
\hline Certos resíduos tais como metais pesados, não são eliminados pelos processos \\
biológicos (embora muitos metais possam ser biorreduzidos ou bio-oxidados para \\
menos tóxicos e formas menos móveis); \\
Pode requerer monitoramento extensivo; \\
Requisitos e eficiência de remoção podem variar consideravelmente de um local para \\
outro; \\
Alguns contaminantes podem estar presentes em altas concentrações que inibem os \\
microrganismos; \\
Há um risco para acumulação de produtos tóxicos da biodegradação;
\end{tabular}

Fonte: Adaptado de Decesaro (2013, p.14).

Portanto, para que a técnica de biorremediação seja eficiente, requer o entendimento de fatores específicos do local, limitando-se a biotransformações ${ }^{3}$ desejáveis em que não haja efeitos inesperados, tais como, a produção de metabólitos ${ }^{4}$ tóxicos e formação de condições ambientais adversas, como: pH elevado, temperatura inadequada, ou presença de metais pesados em concentrações tóxicas que inibam as atividades microbianas específicas (DECESARO, 2013).

\subsubsection{Etapas para implementação do uso da biorremediação}

Para que haja a implementação da biorremediação, algumas etapas tornam-se importantes como: o estudo do ambiente, o tipo de contaminante, os seus riscos e a legislação vigente. Conforme será detalhada no Fluxograma 1.

A etapa inicial de análise consiste na caracterização do tipo e da quantidade do contaminante, assim como avaliações de ordem biológica, geológica, geofísica e hidrológica do

\footnotetext{
${ }^{3}$ Biotransformações são definidas como um conjunto de reações químicas catalisadas por enzimas, células ou tecidos de origem vegetal, microbiana ou animal.

${ }^{4}$ Os Metabolitos são os produtos intermediários das reações metabólicas catalisadas pelas várias enzimas.
} 
sítio (local) contaminado. As primeiras avaliações biológicas ocorrem em laboratórios, tendo como principal objetivo a otimização da biodegradação do poluente.

Para essas avaliações empregam-se dois tipos de testes, o bioestímulo que consiste na adição de nutrientes e/ou surfactantes, e o bioaumento pela adição de culturas de microrganismos biodegradadores. A partir dos dados obtidos, têm-se a escolha da técnica de biorremediação mais adequada para cada situação. Para verificar a eficiência do processo in situ, novos testes de campo são realizados (GAYLARDE; BELLINASO; MANFIO, 2005).

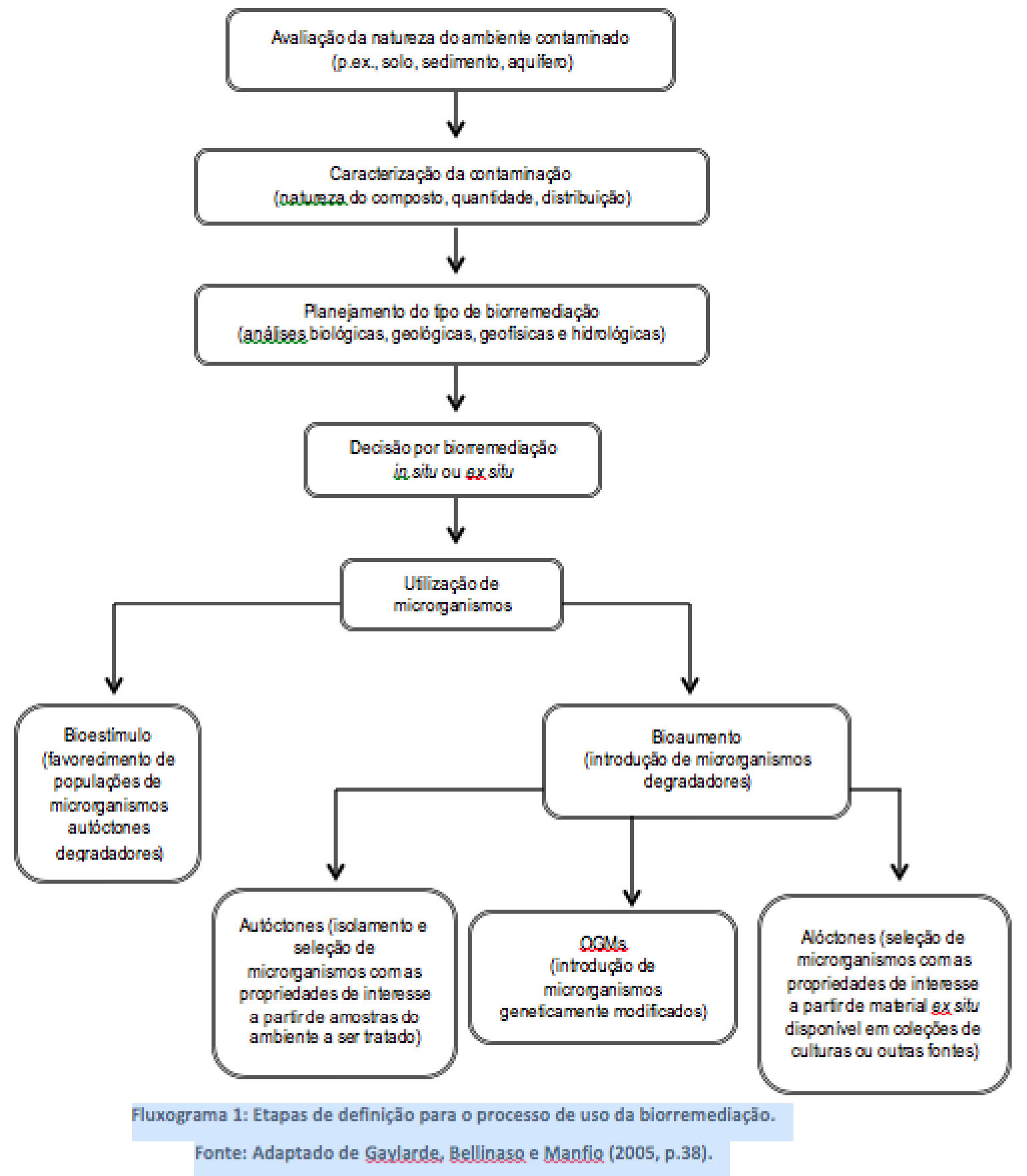




\subsubsection{Mecanismos aplicados à biorremediação}

\subsubsection{Biorremediação in situ}

Esta técnica consiste no tratamento do solo no local da contaminação, utilizando-se de processos que vão da inserção de oxigênio e nutrientes até a adição de organismos específicos para cada tipo de contaminante.

Desta forma não se faz o uso da remoção do material contaminado, evitando custos e distúrbios ambientais do solo. Os produtos finais de uma biorremediação eficaz são a água (H2O) e o dióxido carbônico ( $\mathrm{CO} 2$ ), que não apresentam toxidade ao meio ambiente.

De acordo com os parâmetros existentes que são: origem dos microrganismos, acréscimo ou não de nutrientes, poderá ser empregada a biorremediação in situ por meio de três técnicas: Biorremediação intrínseca; bioestímulo e o bioaumento (GAYLARDE; BELLINASO; MANFIO, 2005; MARIANO, 2006; MUTECA, 2012).

\subsubsection{Biorremediação ex situ}

O processo de biorremediação ex situ em solos contaminados pela indústria do petróleo é composto por vários processos: landfarming, bioestímulo, bioaumento e biorreatores. Esses processos fazem uso de unidades móveis e estações fixas de tratamento para promoverem a descontaminação do ambiente.

Estes processos por sua vez, possibilitam resultados mais rápidos por terem um maior controle dos níveis de temperatura, presença de oxigênio, nutrientes, e pH. Além disso, apresentam uma maior versatilidade para o tratamento de um número maior de contaminantes e tipos de solo. Contudo, requerem a escavação e a remoção do solo contaminado para outro local, o que com isso eleva o custo do tratamento (ANDRADE; AUGUSTO; JARDIM, 2010; MUTECA, 2012).

\subsubsection{Biorremediação Intrínseca}

A biorremediação intrínseca ou atenuação monitorada baseia-se no monitoramento da capacidade de biodegradação dos microrganismos nativos degradarem o contaminante, sem que haja o acréscimo de nutrientes ou qualquer adequação do ambiente. Logo, os microrganismos no local passam a se utilizar do contaminante como fonte de carbono (energia) para reduzir com o tempo os níveis de concentração.

Dessa forma, segundo Mariano (2006), este processo vem ganhando aceitação, sobretudo, em locais contaminados por petróleo e seus derivados. Este processo está relacionado diretamente aos processos físicos, químicos e biológico o que facilita o processo de remediação de maneira global.

No entanto, a biorremediação intrínseca por depender exclusivamente de processos naturais, torna o seu processo bastante lento, o que exige o uso em conjunto de outras técnicas, bem como o monitoramento por um período longo de tempo (CARNEIRO; GARIGLIO, 2010).

\subsubsection{Bioaumento}

De acordo com Mariano et al. (2007) e Yakubu (2007), esta técnica pode ser utilizada tanto in situ quanto ex situ. Ela consiste na adição de microrganismos específicos em regiões impactadas, 
sendo adequadas às condições do ambiente em laboratório. Garantindo dessa forma que o consórcio adequado de microrganismos estará presente em tipo, número e compatibilidade suficientes, a fim de metabolizar o poluente de forma eficaz.

\subsubsection{Bioestímulo}

O método da bioestimulação pode ser empregado tanto in situ quanto ex situ. Todavia, este só se faz eficaz quando existem populações microbianas degradadoras no contaminante (YAKUBU, 2007). Esta técnica realiza o estimulo microbiano nativo, otimizando suas condições de crescimento por intermédio da adição de nutrientes orgânicos e inorgânicos, regulação de pH, temperatura e aeração (MARIANO et al., 2007; YAKUBU, 2007).

\subsubsection{Landfarming}

Landfarming é uma tecnologia de remediação utilizada para o tratamento de resíduos oleosos na superfície do solo que visa à redução das concentrações de hidrocarboneto por meio da biodegradação microbiana. O solo contaminado é escavado em finas camadas e espalhado sobre a sua superfície, onde acontece a estimulação microbiana aeróbica por meio da aeração, nutrientes e umidade (MOREIRA, 2011; MUTECA, 2012).

Para Doelman e Breedvelk (1999 apud JACQUES et al., 2007), a técnica pode ser realizada in situ, que visa a descontaminação do solo no próprio local, ou ex situ, que realiza à remoção no contaminante para outro local onde, também, será feito o processo de descontaminação.

Nos Estados Unidos foi à primeira técnica ex situ empregada em larga escala. O seu processo tem maior eficácia e sucesso quando a área é contaminada com substâncias de fácil degradação aeróbica (BERGER, 2005).

\subsubsection{Biorreatores}

Os biorreatores têm como diferencial entre as técnicas ex situ, o tratamento produzido em um ambiente fechado, o reator. $O$ que por sua vez, apresenta uma maior vantagem de degradação biológica devido ao seu fácil controle, o que permite com que o tratamento torne-se rápido e profícuo. Além disso, as concentrações de oxigênio, nutrientes, teor de água, temperatura e pH são monitoradas em tempo real (BERGER, 2005).

No entanto, para Berger (2005) e Muteca (2012), os custos desse tratamento por meio de biorreatores tornam-se bastante elevado, devido ao deslocamento do material contaminado, seguido de um alto consumo energético e da necessidade de equipamentos sofisticados. No entanto, esta técnica é extremamente importante para a degradação de compostos altamente recalcitrantes. Porém, a sua aplicabilidade comercial no Brasil ainda não existe.

\section{METOdOLOGIA}

Com base em um estudo bibliográfico detalhado, com o objetivo de analisar a atividade petrolífera e seus impactos no meio ambiente, expor e analisar os processos que compõem a biorremediação seja in situ ou ex situ que se realizou este estudo. A perspectiva do presente trabalho baseia-se na análise dos processos de biorremediação para redução de contaminantes presentes no petróleo produzido, bem como a melhora no âmbito social e ambiental, visto que os 
contaminantes do petróleo em geral causam degradação da fauna e flora. O Fluxograma 2 representa a estrutura organizacional do desenvolvimento deste trabalho.

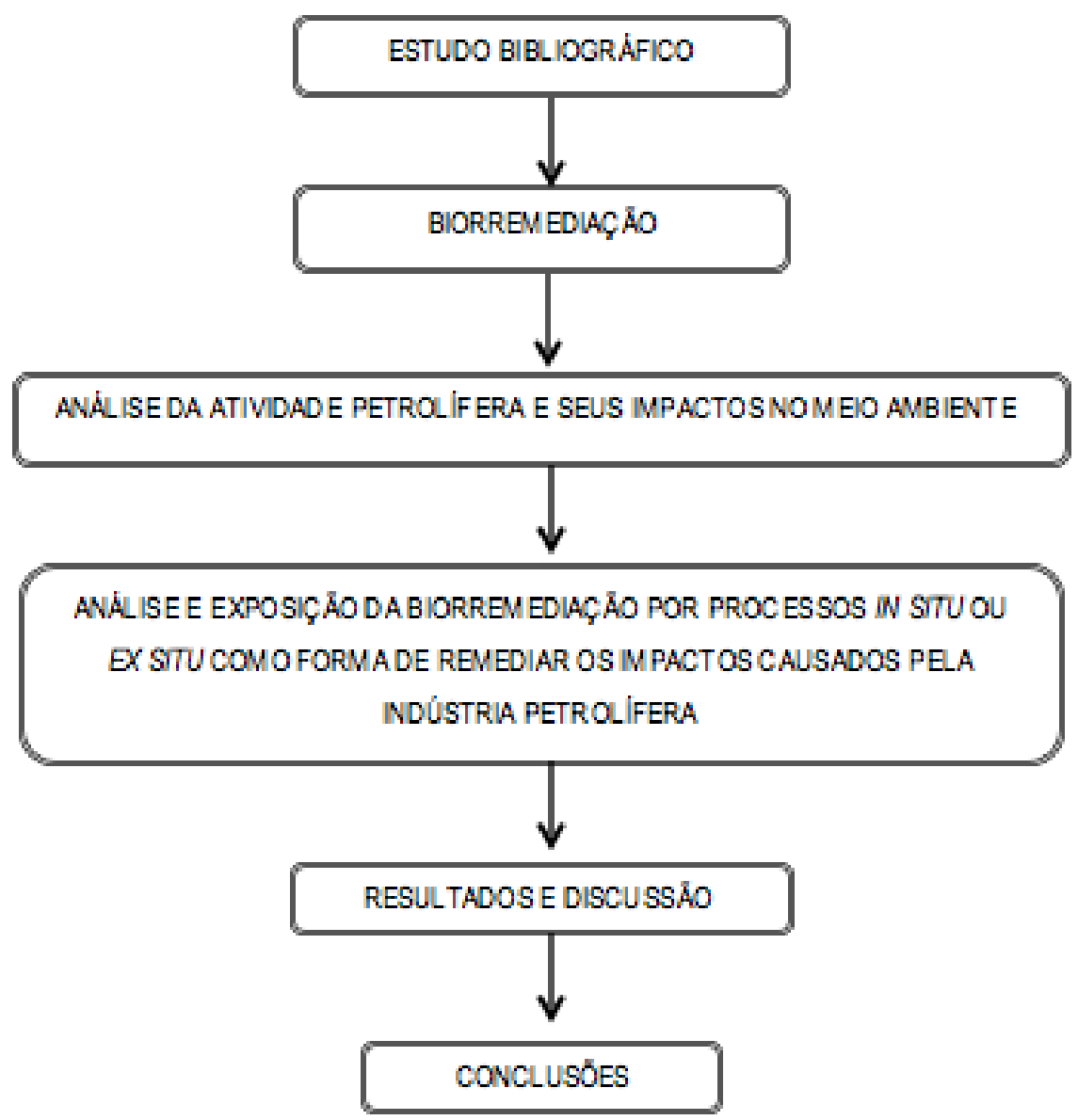

Fluxograma 2: Processo metodológico utilizado no âmbito deste trabalho.

Fonte: Autor.

\section{RESULTADOS E DISCUSSÃO}

A biorremediação vem sendo empregada em grande parte do mundo, visando à redução dos impactos causados pela indústria petrolífera. A seguir serão mostradas respectivamente, algumas de suas aplicações mais proeminentes, Antártida, Estados Unidos e China. No Brasil a sua aplicação vem sendo disseminada.

\subsection{BIORREMEDIAÇÃO NA ANTÁRTIDA}

Ao longo das últimas décadas, foram comprovados que em diferentes sistemas (solo, água doce, água do mar), que comunidades bacterianas nativas, mesmo em frações pequenas se proliferam na presença de hidrocarbonetos. O tamanho de cada comunidade depende de fatores bióticos e abióticos diferentes, assim como da capacidade de adaptação dos microrganismos aos hidrocarbonetos, pois caso não ocorra esta adaptação, não se obterá o processo de biorremediação. 
Além disso, bactérias isoladas e inoculadas não conseguem sobreviver e desenvolver o processo de biodegradação por se encontrarem em condições climáticas extremas, condições essas, como o próprio frio da antártica. Logo, os processos de biodegradação de poluentes orgânicos em solos da Antártica são mais difíceis de alcançar do que aqueles em áreas mais temperadas. No entanto, os únicos microrganismos capazes de realizar a biorremediação em ambientes gélidos são os psicrófilos e psicrotolerantes (bactérias tolerante às baixas temperaturas) provenientes do bioaumento, conseguindo com êxito a remoção de poluentes em temperaturas baixas (RUBERTO; VAZQUEZ; CORMACK, 2003).

No estudo realizado por Ruberto, Vazquez e Cormack (2003) o combustível mais comumente utilizado nas estações da Antártica é o diesel, este, por sua vez, foi removido de forma significativa a partir de solos expostos a temperaturas variando entre $0^{\circ} \mathrm{C}$ e $10^{\circ} \mathrm{C}$. Com isso, foi-se empregado o bioestímulo por meio de nutrientes como nitrogênio $(\mathrm{N})$ e fósforo $(\mathrm{P})$, método realizado há várias décadas para estimular as bactérias no ambiente afetado.

Portanto, o estudo realizado pelos autores mostrou que a microbiota bacteriana nativa de solos da Antártica é capaz de degradar uma fração relevante de hidrocarbonetos (contaminantes). Contudo, a cepa isolada contendo as bactérias psicrotolerantes se mostrou demasiadamente importante na eliminação do diesel e outros combustíveis ricos em alifáticos que representam as principais fontes de poluição próximas às estações.

Apesar do fato de que a introdução de espécies não nativas ainda não é aceita atualmente na Antártida, as bactérias psicrotolerantes obtiveram uma maior eficiência em condições climáticas difíceis, tornando-se uma ferramenta interessante na evolução de trabalhos futuros utilizando o processo de bioaumento em outras áreas de baixas temperaturas.

\subsection{BIORREMEDIAÇÃO NOS ESTADOS UNIDOS E CHINA}

Assim como na Antártica, ou em qualquer tipo de localidade, para que ocorram níveis ótimos de biorremediação, se faz necessário conhecer as características de concentração do óleo residual, a densidade populacional dos microrganismos degradarem o petróleo e o seu potencial de biodegradação.

No estudo pertinente aos Estados Unidos e China houve a comparação entre os métodos de biorremediação no processo de descontaminação de solos contaminados por óleo diesel, foram eles, a atenuação monitorada, bioestímulo e bioaumento. Os solos contaminados por óleo diesel foram coletados a partir de Long Beach, Califórnia (EUA) e Hong Kong (China). (BENTO et al., 2005).

A partir disso, Bento et al. (2005) realizaram três tipos de tratamentos já supracitados, para avaliar a eficiência de degradação desse óleo. A degradação de hidrocarbonetos totais de petróleo (TPH) foi maior na amostra de solo de Long Beach do que no solo Hong Kong. Porém, o solo de Hong Kong levou cerca de 2 semanas para atingir apenas 50\% da degradação, sendo esse, mediado pelo processo de atenuação monitorada e isso ocorreu devido o tempo de incubação, que é o período necessário para o crescimento bacteriano seja suficiente para dar início a ação degradante. Comparado a isso, o solo de Long Beach demonstrou logo na primeira semana, porcentagens de degradação.

Entre os tratamentos promovidos pela biorremediação foi notado que ao utilizar o bioaumento, que consiste na inserção de um consorcio de bactérias pré-selecionadas, as taxas de 
degradação para frações leves de TPH oriundas do solo Long Beach estavam maiores, cerca de, 63 a $84 \%$. Com a adição de nutrientes, que se destina ao processo de bioestímulo, para esse solo, obteve-se uma degradação significativa de $72 \%$ das frações leves em apenas seis semanas de incubação.

Já no solo Hong Kong, o processo de atenuação monitorada resultou em uma maior degradação da fração leve de TPH em 47\%. Para que houvesse a degradação da fração pesada de TPH no solo de Hong Kong, empregaram-se, também, os processos de bioaumento e bioestímulo, o que resultou após 12 semanas em cerda de 30,1\% (bioaumento) e 28 a 31\% (bioestímulo) de sua degradação.

Os tratamentos da biorremediação afetaram, do mesmo modo, a degradação da fração pesada do TPH em ambos os solos, embora no solo Long Beach tenha sido maior. O modelo de degradação neste solo foi semelhante às frações leves. Após 12 semanas, mediante a atenuação natural, a degradação da fração pesada no solo Long Beach diminuiu significativamente.

Quando os dois solos foram comparados, a amostra Long Beach em ambas as frações de TPH resultaram em uma maior degradação. Já no solo Hong Kong a uma maior porcentagem de degradação das frações leves foi encontrada no processo de atenuação natural. Contudo, na fração pesada, a porcentagem de degradação promovida pelo bioestímulo no solo de Hong Kong, equiparou-se aos resultados anteriores do bioaumento, visto na décima segunda semana. Entretanto, sua taxa semanal de degradação mostrou ter uma eficiência duas vezes maior do que a do solo Long Beach, que se utilizou de consórcios de bactérias isoladas (bioaumento).

Após 12 semanas de incubação que foi período final da experiência, o solo recolhido de Long Beach na Califórnia mostrou a maior degradação de TPH, atingindo valores de $70 \%$.

Por outro lado, o solo de Hong Kong não atingiu resultados tão satisfatórios na biodegradação dos componentes de TPH com a utilização do bioaumento e bioestímulo. Foi observado que a degradação de TPH na última atividade microbiana do solo, tornou-se mais elevada sobre a atenuação natural, o que indica que os microrganismos nativos do solo foram limitados pela ação das bactérias não nativas. Apesar disso, o solo Hong Kong, por intermédio da atenuação natural resultou em maior degradação da fração leve de TPH. E o sucesso da biorremediação depende do estado de adaptação metabólica e genética das populações microbianas ao seu ambiente.

Dessa forma, o estudo realizado por Bento et al. (2005), afirma que por meio do bioaumento o solo Long Beach obteve o melhor desempenho para a degradação do óleo diesel. No entanto, os autores afirmam também, que para que exista um melhor desempenho do bioaumento, este, deve ser utilizado com microrganismos já existentes no ambiente, com isso haverá um aumento da população microbiana especifica, e para reduzir o tempo, se faz o uso da adição de nutrientes (bioestímulo), e como os microrganismos nativos já estão adaptados ao próprio ambiente poderão garantir uma rápida degradação do contaminante.

\subsection{BIORREMEDIAÇÃO NO BRASIL}

Os autores Trindade et al. (2005), destacaram que assim como no Brasil e em grande parte do mundo, os riscos de derramamento de óleo provenientes a partir de várias atividades da 
indústria do petróleo, vem causando sérios problemas ao meio ambiente, poluições variantes entre ar, água e contaminação no solo.

Os autores compararam a eficiência na degradação obtida a partir da aplicação de técnicas de bioaumento e bioestímulo em solos brasileiros (Estado de São Paulo), sendo um com histórico de contaminação por óleo cru ao longo de quatro anos; e outro sendo uma amostra de um solo recentemente contaminada, ambos sob condições tropicais.

Trindade et al. (2005) afirmam que o solo contaminado com óleo por longo período normalmente contém compostos de frações recalcitrantes (moléculas de difícil degradação), por sua cadeia de hidrocarbonetos possuírem um elevado peso molecular (maiores do que os compostos (25), por sua vez, os microrganismos indígenas não terão a capacidade metabólica necessária para degradá-lo. Em contraste, um solo contaminado com óleo recentemente contém uma maior quantidade de compostos alifáticos e saturados, os quais são os mais susceptíveis à degradação microbiana. No entanto, compostos poluentes em um solo contaminado recentemente são mais potencialmente tóxicos para os microrganismos nativos, o que conduz à adaptação lenta, antes de degradar o poluente e até mesmo a uma inibição do processo de biodegradação.

A otimização das condições utilizadas estimularam a biodegradação de solos intemperizados e de solos recentemente contaminados de São Paulo, levando ao aumento da mineralização do óleo e à remoção de frações do mesmo em ambos os solos (Trindade et al. 2005). Esse trabalho contribui para o entendimento sobre a ocorrência e a biodegradação de solos tropicais, onde o intemperismo é um fenômeno relevante.

Portanto, fica claro o sucesso do emprego das técnicas de biorremediação. No entanto, para que se chegue ao êxito, é de suma importância que se faça um estudo detalhado das características do ambiente, assim como do tipo de contaminante. Para posteriormente, empregar o método mais adequado para cada cenário.

\section{CONCLUSÕES}

Embora o petróleo ainda seja a maior fonte energética do planeta, seus principais processos de exploração e explotação têm degradado intensamente o meio ambiente. Os seus danos mais significativos ocorrem durante o seu transporte, seja ele em forma de petróleo bruto ou em suas frações derivadas.

Dessa forma, a biorremediação surgiu com a finalidade de promover a descontaminação dessas áreas, e para isso, utiliza-se de microrganismos na degradação do petróleo e seus derivados, reduzindo de forma significativa, os impactos oriundos da indústria do petróleo. Essa técnica já é bastante empregada em países desenvolvidos como Estados Unidos e parte da Europa. No Brasil sua aplicação ainda é pouco usual, porém pode ser largamente utilizada em solos brasileiros, sobretudo, por suas condições climáticas típicas.

Portanto, este trabalho expôs e analisou informações sobre essa tecnologia, comparando estudos realizados em diferentes locais, inclusive em solos brasileiros, evidenciando o seu potencial nos processos de descontaminação de áreas contaminadas por petróleo e derivados. Contudo, não se pode asseverar que um método torna-se mais relevante do que o outro, tendo em vista que para que ocorram níveis ótimos de biorremediação, é impreterível conhecer as 
características de concentração do contaminante, assim como a densidade populacional dos microrganismos que interagem com o petróleo e o seu potencial de biodegradação.

Dessa forma, é de suma importância um estudo continuado sobre essa temática, o que com isso, possibilitará novas linhas de pesquisa, as quais podem ser relacionadas à viabilidade econômica da técnica, otimização dos processos que a compõem, seja, in situ ou ex situ e análise dos percentuais de degradabilidade dos microrganismos nativos.

\section{REFERÊNCIAS}

1. ANDRADE, J. A.; AUGUSTO, F.; JARDIM, I. C. S. F. Biorremediação de solos contaminados por petróleo e seus derivados. Eclética Química, Campinas, p.17-43, 2010. Disponível em: <http://www.scielo.br/scielo.php?pid=S0100-46702010000300002\&script=sci_arttext>. Acesso em: 12 jul. 2015.

2. BENTO, F. M. et al. Comparative bioremediation of soils contaminated with diesel oil by natural attenuation, biostimulation and bioaugmentation. Bioresource Technology, [S.I.], v. 96, n. 9, p.1049-1055, jun. 2005.2 Disponível em: <http://www.sciencedirect.com/science/article/pii/S0960852404003220>. Acesso em: 19 set. 2015.

3. BERGER, T. M. Biorremediação de solos contaminados com hidrocarbonetos totais de petróleo: enfoque na aplicação do processo Terraferm. Tese (Doutorado em Ecologia) Universidade Federal do Rio Grande do Sul, Porto Alegre. 86p. 2005. Disponível em:<http://www.lume.ufrgs.br/bitstream/handle/10183/10900/000590396.pdf?s>. Acesso em: 22 jul. 2015.

4. BOSSOLAN, N. R. S. Introdução á Microbiologia. 2002. 64 f. TCC (Graduação em Curso de Microbiologia) - Universidade de São Paulo Instituto de Física de São Carlos Licenciatura em Ciências Exatas, [S.I.], 2002. Disponível em: <http://iseib.edu.br/biblioteca/wpcontent/uploads/2013/05/INTRODU\%C3\%87\%C3\%830-\%C3\%80-MICROBIOLOGIA.pdf> Acesso em: 29 jul. 2015.

5. CARDOSO, L. C. Petróleo do poço ao posto. Rio de Janeiro: Qualitymark Editora Ltda, 2005.

6. COSTA FILHO, G. F. Biodegradação de Óleos Derivados do Petróleo e de Origem Vegetal Estimulada por Biossurfactantes em Meio Aquoso e Monitoramento de sua Toxicidade. 2011. 68 f. TCC (Graduação em Curso de Ecologia) - Universidade Estadual Paulista "Júlio de Mesquita Filho", Rio Claro, 2011. Disponível em: <http://repositorio.unesp.br/bitstream/handle/11449/118752/costafilho_gf_tcc_rcla.pdf?se quence=1>. Acesso em: 10 ago. 2015.

7. CARNEIRO, Danielle de Arruda; GARIGLIO, Lucas Paulo. A biorremediação como ferramenta para a descontaminação de ambientes terrestres e aquáticos. Tecer, Belo Horizonte, v. 3, n. 4, p.82-95, 2010. Disponível em: <http://www.bibliotekevirtual.org/revistas/MetodistaIH/RT/v03n04/v03n04a08.pdf>. Acesso em: 28 set. 2015.

8. DECESARO, A. Bioestimulação de solo contaminado por compostos oleosos com biomassa microbial inativa. 2013. 60 f. TCC (Graduação em Curso de Engenharia Ambiental) - Faculdade de Engenharia e Arquitetura da Universidade de Passo Fundo, Passo Fundo, 2013. Disponível em: <http://usuarios.upf.br/ engeamb/TCCs/2013-1/Andressa\%20Decesaro.pdf>. Acesso 
em: 13 ago. 2015.

9. GAYLARDE, C. C.; BELLINASO, M. L.; MANFIO, G. P. Biorremediação. Biotecnologia Ciência \& Desenvolvimento, n. 34, p. 36-43, 2005. Disponível em: <http://www.cocminas.com.br/arquivos/file/Biorremediacao.pdf>. Acesso em: 3 ago. 2015.

10. JACQUES, R. J. S. et al. Biorremediação de solos contaminados com hidrocarbonetos aromáticos policíclicos. Ciência Rural, Santa Maria, v. 37, n. 4, p.1192-1201, 2007. Disponível em: <http://www.scielo.br/pdf/cr/v37n4/a49v37n4.pdf>. Acesso em: 23 ago. 2015.

11. MANFIO, G. P. Avaliação do estado do conhecimento da diversidade biológica do Brasil: Microbiota. $2003 . \quad$ Disponível em: <http://www.sifloresta.ufv.br/bitstream/handle/123456789/12145/Livro_Avalia\%C3\%A7\%C 3\%A3o-do-Estado-do-Conhecimento-da-Diversidade-Biol\%C3\%B3gica-do-BrasilMicrobiota_MMA.pdf?sequence=1\&isAllowed=y>. Acesso em: 8 abr. 2015.

12. MARIANO, A. P. Avaliação do potencial de biorremediação de solos e de águas subterrâneas contaminados com óleo diesel. 2006. 162 f. Tese (Doutorado em Geociências e Meio Ambiente) - Universidade Estadual Paulista, Rio Claro, SP, 2006. Disponível em: <http://www.researchgate.net/profile/Adriano_Mariano2/publication/36362353_Avaliao_d o_potencial_de_biorremediao_de_solos_e_de_guas_subterrneas_contaminados_com_leo_ diesel/links/00b49531b5b5368f03000000.pdf>. Acesso em: 23 jun. 2015.

13. MARIANO, A.P.; KATAOKA, A.P.A.G.; ANGELIS, D.F. \& BONOTTO, D.M.

14. Laboratory study on the bioremediation of diesel oil contaminated soil from a petrol station. Brazilian Journal of Microbiology, v.38, p.346-353, 2007. Disponível em: <http://www.scielo.br/pdf/bjm/v38n2/v38n2a30.pdf>. Acesso em: 11 set. 2015.

15. MOREIRA, Í. T. A. Avaliação da eficiência de modelos de remediação aplicados em sedimentos de manguezal impactados por atividades petrolíferas. 2011. $163 \mathrm{f}$. Dissertação (Mestrado) - Curso de Geoquímica: Petróleo e Meio Ambiente, Universidade Federal da Bahia, Salvador, 2011. Disponível em: <http://www.pospetro.geo.ufba.br/dissertacoes/DISSERTA_I MOREIRA.pdf>. Acesso em: 29 set. 2015.

16. MUTECA, F. L. L.; Biorremediação de solo contaminado com óleo cru proveniente de Angola. Dissertação (Mestre em Tecnologia de Processos Químicos e Bioquímicos) - Programa em Tecnologia de Processos Químicos e Bioquímicos, Universidade Federal do Rio de Janeiro, Rio de Janeiro, 2012. Disponível em: < http://tpqb.eq.ufrj.br/download/biorremediacao-de-solocontaminado-com-oleo-cru.pdf>. Acesso em: 28 ago. 2015.

17. MYERS, N. Environmental services of biodiversity. Proceedings of the National Academy of Sciences, v. 93, n. 7, p. 2764-2769, 1996. Disponível em: <http://www.pnas.org/content/93/7/2764.full.pdf>. Acesso em: 14 set. 2015.

18. RUBERTO, L.; VAZQUEZ, S. C.; CORMACK, W. P. M. Effectiveness of the natural bacterial flora, biostimulation and bioaugmentation on the bioremediation of a hydrocarbon contaminated Antarctic soil. International Biodeterioration \& Biodegradation, [S.I.], v. 52, n. 2, p.115-125, set. 2003.2 Disponível em: <http://www.sciencedirect.com/science/article/pii/S0964830503000489>. Acesso em: 19 set. 2015.

19. SANTOS, P. V. Impactos ambientais causados pela perfuração em busca do petróleo. Caderno de Graduação-Ciências Exatas e Tecnológicas-UNIT, v. 1, n. 1, p. 153-163, 2012. Disponível 
em: <https://periodicos.set.edu.br/index.php/cadernoexatas/article/view/297>. Acesso em: 10 ago. 2015.

20. SILVA, J. M. C. et al. Impactos Ambientais da Exploração e Produção de Petróleo na Bacia de Campos, RJ. In: ENCONTRO NACIONAL DA ANPPAS 4, Brasília, p.1-19, 2008. Disponível em: <http://www.anppas.org.br/encontro4/cd/ARQUIVOS/GT4-809-870-20080518190501.pdf>. Acesso em: 17 ago. 2015.

21. THOMAS, J. E. (Org.) Fundamentos de engenharia de petróleo. Rio de Janeiro: Interciência, 2004.

22. TRINDADE, P.V.O. et al. Bioremediation of a weathered and a recently oil-contaminated soils from Brazil: a comparison study. Chemosphere, [s.l.], v. 58, n. 4, p.515-522, jan. 2005. Disponível em: <http://www.sciencedirect.com/science/article/pii/S0045653504007908>. Acesso em: 20 set. 2015. 